\title{
Can calories from ethanol contribute to body weight preservation by malnourished rats?
}

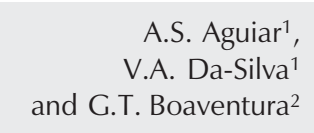

Correspondence

V.A. Da-Silva

Departamento de Fisiologia e

Farmacologia, UFF

Rua Hernani Pires de Mello, 101

24210-130 Niterói, RJ

Brasil

E-mail: vilma@urbi.com.br

Presented at the XVIII Annual Meeting of the Federação de Sociedades de Biologia Experimental, Curitiba, PR, Brazil, August 27-30, 2003.

Research support by CNPq. .....................

Received May 6, 2003 Accepted February 11, 2004 . . . . . . . . . . . .

\author{
${ }^{1}$ Núcleo de Ciências Comportamentais e do Desenvolvimento, \\ Departamento de Fisiologia e Farmacologia, and \\ ${ }^{2}$ Laboratório de Nutrição Experimental, Departamento de Nutrição e Dietética, \\ Universidade Federal Fluminense, Niterói, RJ, Brasil
}

\begin{abstract}
Our objective was to compare the use of calories from ethanol by wellnourished and malnourished rats in terms of body weight. Female Wistar rats weighing 170-180 $\mathrm{g}$ at the beginning of the study were used. The animals were divided into two groups $(\mathrm{N}=12$ each): group $\mathrm{W}$ received water ad libitum and group $\mathrm{E}$ an ethanol solution ad libitum as the only source of liquid throughout the experiment. The concentration of ethanol was increased weekly from 0 to 5, 10, 20 and $40 \%(\mathrm{v} / \mathrm{v})$. In the well-nourished phase (A), all rats received food ad libitum (AW and $\mathrm{AE}$ ). Ethanol treatment (AE) was then interrupted and water was offered to both groups. After 2 weeks both AW and AE rats were submitted to food restriction (50\% of group AW food consumption), thus initiating the malnutrition phase (M). Liquid was offered as described before to the same W (MW) and E (ME) groups. The weight gain during the 1-week treatment of AE rats was similar to that of AW animals only when AE rats received the 5\% (v/v) ethanol solution (9.16 vs $10.47 \mathrm{~g})$. Weight loss was observed after exposure to $10 \%$ ethanol $(\mathrm{P}<0.05)$ in spite of maintenance of caloric intake. Malnourished rats presented weight loss, which was attenuated by ethanol intake up to the $20 \%(\mathrm{v} / \mathrm{v})$ solution and was related to an increased caloric offer. This effect was not observed with the $40 \%$ ethanol solution (-9.98 g). These data suggest that calories from ethanol were used to maintain body weight up to the concentration of $10 \%$ (v/v) (well-nourished) and 20\% (v/v) (malnourished) and that ethanol has a toxic profile which depends on nutritional status.
\end{abstract}

Key words

- Ethanol

- Weight gain

- Malnutrition

- Rats

- Toxicity
In terms of caloric content, ethanol is a unique drug whose oxidation by alcohol dehydrogenase $(\mathrm{ADH})$ produces $7.1 \mathrm{kcal}$ per gram of ethanol oxidized. However, it is not known to what extent these calories are converted into body weight. There is no controversy about the malnutrition produced by chronic ethanol in- take in alcoholics. In addition to the known toxic effects on absorption and synthesis of essential nutrients (1), some important metabolic changes occur. Pirola and Lieber (2) reported that activation of the microsomal ethanol oxidizing system (MEOS) in hepatocytes of alcoholics may consume one third of the 
caloric content of ethanol and impair ATP synthesis. Lands and Zakhari (3) suggested the existence of a futile cycle in ethanol metabolism which would account for a loss of six ATPs per gram of ethanol oxidized. They proposed that ethanol may be oxidized to acetaldehyde, consuming three ATPs, and acetaldehyde may be again reduced to ethanol, consuming three extra ATPs.

However, there is some controversy about what happens to ethanol calories when consumption is moderate and not related to the metabolic changes of the liver that characterize chronic ethanol intake. It has been suggested that calories derived from ethanol may function as do calories derived from carbohydrates, producing a thermogenesis value of about $10 \%(4,5)$. This thermogenic value may be higher than that of fatty food $(3 \%)$ and lower than that of proteins (about 20\%) (6).

The contribution of calories provided by ethanol to body weight gain has also been studied but there seems to be no consensus about the data from animal and human studies.

Moderate ethanol consumption seems to favor an increase in fat storage and could result in weight gain, especially in overweight individuals (7). In an epidemiological study involving 89,538 women and 48,493 men, Colditz et al. (8) reported a strong negative association between alcohol intake and body weight index for women and the absence of this association for men.

Animal studies are consistent in reporting a decrease in the body weight of rats receiving ethanol solutions as the only source of liquids. Concentrations of ethanol as low as $5 \%(\mathrm{v} / \mathrm{v})$, which are similar to the ethanol content of a Brazilian beer, or as high as $40 \%$ $(\mathrm{v} / \mathrm{v})$, solution similar to spirit drinks, are related to decreased body weight gain (9). Similar results have been reported for $20 \%$ $(\mathrm{v} / \mathrm{v})$ ethanol solution (10).

Different results have been obtained for malnourished animals. Da-Silva et al. (11), studying rats which had been treated with ethanol for 90 days, reported a significant weight gain by malnourished rats $(50 \%$ food restriction) drinking a $20 \%(\mathrm{v} / \mathrm{v})$ ethanol solution when compared to malnourished rats drinking water. A more recent study (12) reported improvement in somatic and motor development and a decrease in the mortality rate of the offspring of malnourished rats drinking low doses of ethanol $(5 \%, \mathrm{v} / \mathrm{v})$. These data suggest that malnourished rats can benefit from ethanol calories.

In summary, in spite of the large number of studies on the effects of ethanol in wellnourished animals and humans, there is still controversy about how well ethanol-derived calories can be utilized. Fewer studies are available about special physiological conditions such as malnutrition. Over the last few years, scientific research has mainly focused on obesity, an increasing problem in developed countries, which led us to the false belief that malnutrition was no longer a problem worth investigating. However, there are still 800 million malnourished people in the world (13). The decreasing interest of the scientific community in problems related to malnutrition has left many questions without an answer. Ethanol consumption and its consequences on the malnourished organism are among them.

In view of the importance of malnutrition in Brazil - $22 \%$ of the population or 40 million people are malnourished (14), as well as ethanol consumption and alcoholism - $11 \%$ of Brazilian population are alcoholics (15), the aim of the present study was to assess the use of ethanol calories in a dose/ effect model by evaluating body weight before and after the installation of malnutrition. We wanted to determine the smallest dose of ethanol that would be toxic in both conditions and used the same animals in the well-nourished and malnourished situation in order to control for individual variation.

The study was designed to test the hypothesis that ethanol calories and toxicity depend on the nutritional status of the animals. Female rats were used as models because of 
the known increased toxicity of ethanol in women and because of the important teratogenic effects of ethanol.

Female Wistar rats (Rattus novergicus) from our colony, weighing 170-180 $\mathrm{g}$ at the beginning of the study, were used. The animals were kept in individual cages and assigned randomly to two groups: water (W, N $=12)$ and ethanol $(\mathrm{E}, \mathrm{N}=12)$. They were fed a standard pellet diet $\left(\mathrm{Nuvital}^{\circledR}\right.$, Nuvilab Ltda., Curitiba, PR, Brazil) ad libitum (A) for five weeks, corresponding to the wellnourished phase. Group AE received an ethanol solution containing ethanol concentrations increased weekly in a stepwise fashion $(0,5,10,20$ and $40 \%, \mathrm{v} / \mathrm{v})$, as the only drinking source. Group AW received tap water ad libitum. After this 5-week period, all rats were offered tap water and food $a d$ libitum for 15 days. Rats were observed for withdrawal symptoms. After ethanol detoxification, all rats were submitted to food restriction of $50 \%$ of the ad libitum consumption for 5 weeks (malnourished phase) and ethanol was restarted following the same procedure as described before. Food and fluid intake, as well as body weight were recorded 5 days a week.

The results are reported as means $\pm \mathrm{SD}$. Data were compared by the Student $t$-test, with the level of significance set at $\mathrm{P}<0.05$.

Ethanol intake reduced food intake in $a d$ libitum fed rats in a dose-dependent manner. At the highest dose of ethanol $(40 \%, v / v)$ food intake was only $32 \%$ of that observed among animals that received water (AW: $17.4 \pm 1.4 v \mathrm{~s}$ $\mathrm{AE}: 5.6 \pm 1.8 \mathrm{~g}, t=17.88, \mathrm{P}=0.000$; Figure 1). The same rats, when malnourished, presented a significant reduction in food intake only at the $40 \%(\mathrm{v} / \mathrm{v})$ ethanol concentration, when they consumed $83 \%$ of the food offered. Mean $( \pm \mathrm{SD})$ food intake by malnourished animals drinking water (MA) and malnourished animals drinking ethanol (ME) was $8.31 \pm 0.15$ and $6.91 \pm 1.96 \mathrm{~g}(t=2.34, \mathrm{P}=0.03)$, respectively. The anorexic effect of ethanol has been extensively reported in the literature (2). The fact that it was detected only at the highest concentration among malnourished rats was probably related to the offer of a small amount of food.

As a general rule, fluid consumption decreased with increasing ethanol concentration both among ad libitum feeding and malnourished rats (Figure 1). However, an interesting finding is that malnourished rats drank significantly more ethanol than water at the $5 \%$ and $10 \%$ ethanol concentrations: MW, $14.1 \pm 2.1 v s$ ME $5 \%, 23.6 \pm 8.2 \mathrm{ml}(t=2.25$, $\mathrm{P}=0.03) ; \mathrm{ME} 10 \%, 21.4 \pm 4.2 \mathrm{ml}(t=2.4, \mathrm{P}$ $=0.02)$. This difference was not observed with 20 and $40 \%(\mathrm{v} / \mathrm{v})$ ethanol.

The increased ethanol intake by malnourished rats can perhaps be explained by the energetic value of the ethanol solution or by the anxiety generated by food restriction. The methods used in the present study involved stressful procedures. Providing ethanol solutions as the only liquid choice may be stressful for rats that dislike the taste of ethanol. This may explain the reduced ingestion of solutions containing increasing ethanol concentrations. On the other hand, malnutrition by food restriction is also stressful

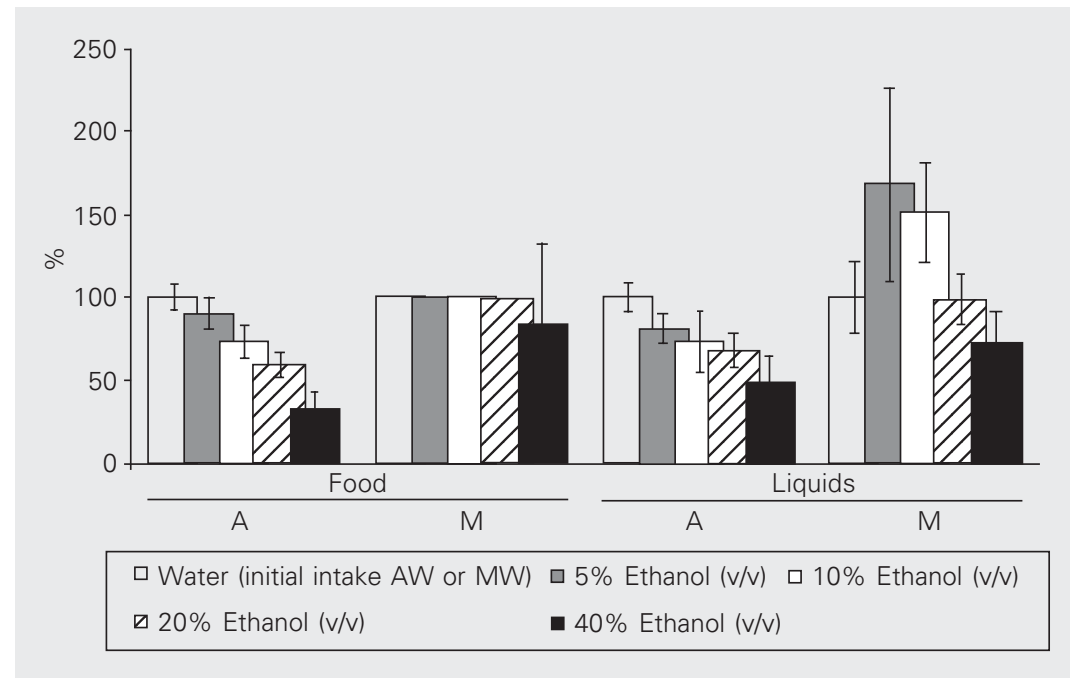

Figure 1. Effect of ethanol concentration in drinking water on food and water intake during the well nourished (A) and malnourished (M) phases. Data are reported as percent intake by the water group (AW and MW) rats. Food $(100 \%)=A W: 17 \mathrm{~g}$ and $\mathrm{MW}: 8 \mathrm{~g}$; liquids $(100 \%)=A W: 26.9 \mathrm{ml}$ and $\mathrm{MW}: 14.1 \mathrm{ml}$. 
and the anxiolytic effects of ethanol should also be considered (12), possibly explaining why malnourished rats drink more ethanol than water. Additional studies aimed at evaluating these stress-related variables would be helpful to clarify this point.

During the well-nourished phase, rats lost weight when drinking ethanol solutions of $10 \%(\mathrm{v} / \mathrm{v})$ concentration or more, with the worst effects being observed at the $40 \%$ (v/ v) concentration. The lowest dose of ethanol $(5 \%)$ had no effect on weight gain (AW vs AE 5\%: $10.47 \pm 5.64 v s 9.16 \pm 4.19 \mathrm{~g}, t=$ $0.48, \mathrm{P}=0.63$; Figure 2). Different results were observed among malnourished rats treated with ethanol. Ethanol consumption significantly attenuated body weight loss up to the concentration of $20 \%(\mathrm{v} / \mathrm{v}$; Figure 2$)$. There seems to be a different threshold of ethanol utilization for well-nourished and malnourished rats. Our data suggest that the thresholds would be 5 and $20 \%$ ethanol concentration, respectively.

It is interesting to consider these data in terms of total caloric intake and body weight gain. Among well-nourished rats, in spite of the reduction in food intake, there was total replacement by calories derived from ethanol at all doses, with a total calorie intake of about $50 \mathrm{kcal} /$ day. From this amount of total calories/day on, at each dose level the proportion of calories provided by food was $87.5,76.5,58.5$ and $36 \%$, respectively, for

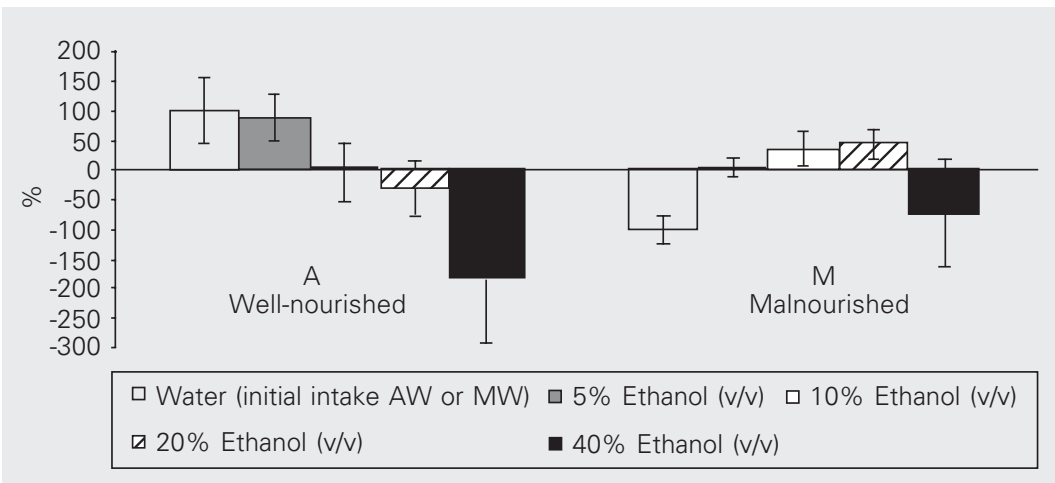

Figure 2. Effect of ethanol concentration in drinking water on weight gain during the wellnourished (A) and malnourished (M) phases. Data are reported as percent weight gain of the water group (AW and MW) rats; $100 \%=\mathrm{AW}: 10.5 \mathrm{~g}$ and $\mathrm{MW}:-13.7 \mathrm{~g}$. ethanol concentrations from 5 to $40 \%$ (v/v). The data indicate that the proportion of calories provided by ethanol in relation to calories provided by food is the determinant factor as far as body weight is concerned.

In the malnourished state, ethanol consumption added to the calories provided by food (MW: $23.96 \pm 0.57 \mathrm{kcal} /$ day; ME 5\%: $30.84 \pm 2.09$; ME 10\%: $36.20 \pm 2.69 ; \mathrm{ME}$ $20 \%: 39.77 \pm 2.45 ; \operatorname{ME~} 40 \%: 42.93 \pm 11.02 ; \mathrm{P}$ $<0.05)$. Calories provided by food represented $78.6,66.7,60.2$ and $46.2 \%$ of the total caloric intake, respectively, for 5 to $40 \%$ ethanol solutions. Therefore, calories from ethanol could be useful for body weight preservation even when they represent $40 \%$ of the total caloric intake. This is about twice as much as observed in the well-nourished state.

When ethanol-derived calories were higher than $50 \%$ of the total intake $(40 \%$ ethanol solution, $\mathrm{v} / \mathrm{v}$ ) even malnourished rats could not utilize this amount to add to body weight, a fact probably related to the toxicity of the highest ethanol concentration (40\%) offered in this experiment. It is known that gastric absorption will be impaired when ethanol concentration in beverages is higher than $10 \%(16)$.

Therefore, the present data suggest that malnourished rats tolerate larger proportions of ethanol calories when body weight is measured. The increased intake of ethanol by malnourished rats can result in higher blood levels and increased systemic toxicity due to exposure of tissues to higher ethanol concentrations. Previous pharmacokinetic studies have shown that ethanol elimination rates do not differ between malnourished and well-nourished rats (17). In agreement with the expected effects of higher ethanol concentrations, the malnourished rats of the present study in fact showed more signs of behavioral intoxication than their ad libitum controls (AE).

Well-nourished rats cannot utilize ethanolderived calories and will lose weight when receiving a $10 \%$ ethanol concentration. Al- 
though the amount of calories ingested by AW and $\mathrm{AE}$ was the same, they were not utilized to the same extent, in agreement with most literature reports on the effects of ethanol. This may be related to the toxicity of ethanol resulting in substrate maldigestion or nutrient malabsorption due to pancreatic, liver and small intestine complications $(16,18)$. Taken together, these effects would result in malnutrition. Additionally, ethanol only produces energy when oxidized by $\mathrm{ADH}$. Literature data suggest that there is a limit for the action of ADH, corresponding to $1.1 \mathrm{~g}$ ethanol per day in rats (10). This is about the amount of ethanol drunk by the rats in the present study at the $10 \%$ ethanol concentration. Higher ethanol levels would activate the MEOS system, which would involve energy expenditure instead of energy production. Another explanation for energy consumption is the dehydration produced by the exclusive consumption of ethanol. It is therefore reasonable that rats drinking ethanol will lose weight.

It is difficult to understand what could be occurring to malnourished rats. Ethanol-derived calories can be used for body weight up to the concentration of $20 \%(\mathrm{v} / \mathrm{v})$. Would the expected toxicity of ethanol previously described be observed only at the highest concentration (40\%)? Daily ethanol consumption was $0.9 \pm 0.3,1.7 \pm 0.3$ and $2.2 \pm$ $0.3 \mathrm{~g}$ at the 5,10 and $20 \%(\mathrm{v} / \mathrm{v})$ concentrations. Was ADH not saturated and was the MEOS not activated as expected at the $1.0 \mathrm{~g} /$ day concentration? Perhaps, the answers to these questions could be found in the important and complex physiological changes that occur when the food restriction model of malnutrition is imposed on rats. Since the restricted amount of food offered is consumed quickly, long periods of fasting would occur. Therefore, we should consider the changes that may occur in metabolism, especially those aimed at preserving the brain under fasting conditions. Since glucose is the only substrate for the brain, when it is not available from the diet, adaptations will be expected to occur in order to provide for it. Gluconeogenesis will occur at a high rate, using glycerol and amino acids as substrates. Only later will the brain adapt to using ketone bodies as substrates and to preserving proteins to some extent. It is reasonable to assume that ethanol calories will delay the proteolytic process by offering energy in the form of acetate and acetyl CoA to systemic functions, thus preserving glucose for brain utilization. Therefore, body weight loss would be retarded, resulting in a decreased weight loss among malnourished rats drinking ethanol. In fact, ADH activity per gram of liver seems to be increased among malnourished rats (17). However, the process of taking calories to preserve body weight would be limited at higher ethanol doses due to the toxicity of the drug and to the well-known limits of the metabolic capacity of ADH.

In summary, the present data show that ethanol calories are used when malnutrition is present, a process occurring at low $(5 \%, \mathrm{v} /$ v) and moderate (10 and $20 \%, v / v)$ ethanol concentrations. Additional biochemical and tissue studies are necessary to determine how this process of energy utilization takes place. It should also be remembered that the etiology of alcoholism is complex and involves genetic and environmental factors. The present data lead us to consider that malnutrition could be a risk factor for alcoholism. Although the data were obtained from an animal model, the increased intake of ethanol observed among malnourished rats, together with the anxiolytic and energetic properties of ethanol, indicate that malnourished subjects may be at increased risk.

\section{Acknowledgments}

We are grateful to Mr. R.A. Laurindo and Mr. D.S. Coutinho for technical assistance, to Prof. L.R. Malheiros for suggestions regarding the manuscript, to Ms. L. Porto for reviewing the text, and to Ms. Luciene for statistical advice. 


\section{References}

1. Lieber CS (1991). Perspectives: do alcohol calories count? American Journal of Clinical Nutrition, 54: 976-982.

2. Pirola RC \& Lieber CS (1976). Hypothesis: energy wastage in alcoholism and drug abuse: possible role of hepatic microsomal enzymes. American Journal of Clinical Nutrition, 29: 90-93.

3. Lands WEM \& Zakhari $S$ (1991). The case of missing calories. American Journal of Clinical Nutrition, 54: 47-48.

4. Murgatroyd PR, Van de Vem M, Goldberg GR \& Prentice AM (1996). Alcohol and the regulation of energy balance: overnight effects on diet-induced thermogenesis and fuel storage. British Journal of Nutrition, 75: 33-45.

5. Sonko BJ, Prentice AM, Murgatroyd PR, Goldberg GR, Van de Vem $M$ \& Coward WA (1994). Effect of alcohol on postmeal fat storage. American Journal of Clinical Nutrition, 59: 619-625.

6. Jéquier $E$ (1999). Alcohol intake and body weight: a paradox. American Journal of Clinical Nutrition, 69: 173-174.

7. Lands WEM (1993). A summary of the workshop "Alcohol and calories: a matter of balance". Journal of Nutrition, 123: 1338-1341.

8. Colditz GA, Giovannucci E, Rimm EB, Stampfer MJ, Rosner B, Speizer FE, Gordis E \& Willet W (1991). Alcohol intake in relation to diet and obesity in women and men. American Journal of Clinical Nutrition, 54: 49-55.

9. Macieira MS, Almeida WG, Silva EA, Schenberg LC \& NakamuraPalacios EM (1997). Alcohol dependence induced in rats by semivoluntary intermittent intake. Brazilian Journal of Medical and Biological Research, 30: 1107-1111.

10. Laure-Achagiotis C, Poussard AM \& Loui-Sylvestre J (1990). Alcohol drinking, food and fluid intakes and body weight gain in rats. Physiology and Behavior, 47: 545-548.

11. Da-Silva VA, Kopelman BI, Macellano MTT, Smigd JS \& Freitas CA (1982). Interação entre a desnutrição e o consumo de etanol antes e durante a gestação: efeitos sobre o desenvolvimento e comportamento da prole de ratos. Jornal de Pediatria, 53: 306-313.

12. Da-Silva VA, Da-Silva JB, Gismondi RAOC \& Rebello GP (2000). Ethanol improves lactation outcome in malnourished rats. Nutritional Neuroscience, 3: 277-282.

13. Food and Agriculture Organization of the United Nations (FAO) (2002). Undernourished around the world: reductions in undernourishment over the past decade. <http: //www.fao.org>, accessed March 16, 2003.

14. Oliveira JED, Cunha SFC \& Marchini JS (1996). A Desnutrição dos Pobres e dos Ricos: Dados Sobre a Alimentação no Brasil. Sarvier, São Paulo, SP, Brasil.

15. Secretaria Nacional Antidrogas - SENAD (2001). 1ํ Levantamento Domiciliar sobre uso de Drogas Psicotrópicas no Brasil. http:// www.senad.gov.br, accessed March 13, 2003.

16. Bode C \& Bode JC (1997). Alcohol's role in gastrointestinal tract disorders. Alcohol Health and Research World, 21: 76-83.

17. Da-Silva VA \& McLean EM (1988). Effect of two different types of malnutrition on the rate of elimination of ethanol in rats. Biochemical Pharmacology, 37: 4235-4238.

18. Morgan MY (1982). Alcohol and nutrition. Medical Bulletin, 38: 2129. 